Editorial

\title{
Everynight Accounting: Nighttime Lights as a Proxy for Economic Performance of Regions
}

\author{
Nataliya Rybnikova 1,2,3 (D)
}

Citation: Rybnikova, N. Everynight Accounting: Nighttime Lights as a Proxy for Economic Performance of Regions. Remote Sens. 2022, 14, 825. https://doi.org/10.3390/ rs14040825

Received: 4 January 2022

Accepted: 17 January 2022

Published: 10 February 2022

Publisher's Note: MDPI stays neutral with regard to jurisdictional claims in published maps and institutional affiliations.

Copyright: (C) 2022 by the author. Licensee MDPI, Basel, Switzerland. This article is an open access article distributed under the terms and conditions of the Creative Commons Attribution (CC BY) license (https:// creativecommons.org/licenses/by/ $4.0 /)$.

\begin{abstract}
Department of Mathematics, University of Leicester, Leicester LE1 7RH, UK; nrybhiko@campus.haifa.ac.il Department of Natural Resources and Environmental Management, University of Haifa, Haifa 3498838, Israel Department of Geography and Environmental Studies, University of Haifa, Haifa 3498838, Israel
\end{abstract}

Artificial nighttime lights, emitted from residential, industrial, commercial and entertainment areas, and captured by satellites, have proven to be a reliable proxy for on-ground human activities. Since the end of the 1990s, nighttime light data have been used to monitor population concentrations and to assess the economic performance of countries and regions (see, for instance, $[1,2]$ ). Since then, studies of this kind have been increasing in an avalanche-like manner, and with nighttime lights being used as a proxy for even more sophisticated things. The reason is that nighttime light data are indeed a very promising tool to catch the patterns of human activities remotely. Specifically, these data are nowadays available for each day and each point on the Earth, thus being more advantageous than traditional estimates, which might be scarce and irregular (due to time-consuming analysis, as in the case of defining the commuting rates), non-unified (due to different national reporting standards), or confidential (due to security reasons or illegality, as in the case of shadow economies).

In the current Special Issue, we have collected ten recent examples for the successful usage of nighttime light data in a variety of socio-economic tasks, for which traditional direct techniques are either inapplicable or inefficient. Thus, Mohammad Reza Farzanegan and Sven Fischer [3], proceeding from the lifting of the international sanctions, proposed using nighttime light data to estimate and model the level of the shadow economy in Iran. John Gibson and Geua Boe-Gibson [4] used DMSP/OLS and VIIRS/DNB nighttime light data to assess their association with disaggregated GDP for various industries at the county level in the USA. Haoyu Liu with co-authors [5] demonstrated the substitution of time-, money-, and labor-consuming GDP data at a county level in the Chinese Mainland by nighttime lights, combined with daytime remote sensing data. VIIRS-provided nighttime lights were used by Nils B. Weidmann and Gerlinde Theunissen [6] to substitute hard-tomeasure and rare data on local economic inequalities in the countries of the Global South. Bingxin Qi, Xuantong Wang, and Paul Sutton [7] combined populational data with the data of nighttime lights to model comparable estimates for educational inequality globally at the national level. Dan Lu, with co-authors [8], using the example of Chongqing municipality in China, proposed an approach to model—via DMSP/OLS and VIIRS/DNB nighttime light data-population dynamics in an agricultural mountainous region. The rest of the studies in the Special Issue are devoted to using nighttime light data for identifying urban extent. Thus, for this purpose, Yuping Wang and Zehao Shen [9], proceeding from the example of eleven urban districts of Nanjing, China, applied a threshold-based Kernel Density Estimator to Luojia 1-01 and VIIRS-provided nighttime light data. Feng Li, with co-authors [10], combined Luojia 1-01 nighttime light data with the Normalized Difference Vegetation and Water Indices to extract data from the urban areas in four capital Chinese cities. Ding Ma with co-authors [11] compared the hotspots, extracted for 20 major Chinese cities, alternatively from the OpenStreetMap platform and VIIRS-provided nighttime light data. Finally, Nataliya Rybnikova with co-authors [12], using the example of two European 
countries, proposed the substitution of the time-consuming mechanism of identifying functional urban areas by optimal thresholds of VIIRS-provided nighttime lights.

We believe that the herein-presented analyses will be useful both for the research community and decision-makers, aiming to better understand the patterns of regional economic development and to design more informed policies. Besides, current studies may provide important insights for engineers, developing and launching satellites for nighttime remote sensing. Specifically, most of the studies in the field (including those of the current Special Issue) use panchromatic data, whereas the potential of multispectral imagery is not fulfilled due to the low availability of the corresponding data.

The Guest Editor is grateful to the Editorial Team for ensuring smooth communication between the authors. I also thank the panel of invited reviewers whose constructive criticism helped to improve the articles and to make them more comprehensive for the reader.

Sincerely,

Nataliya Rybnikova.

Conflicts of Interest: The author declares no conflict of interest.

\section{References}

1. Elvidge, C.D.; Baugh, K.E.; Kihn, E.A.; Kroehl, H.W.; Davis, E.R.; Davis, C.W. Relation between satellite observed visible-near infrared emissions, population, economic activity and electric power consumption. Int. J. Remote Sens. 1997, 18, 1373-1379. [CrossRef]

2. Imhoff, M.L.; Lawrence, W.T.; Stutzer, D.C.; Elvidge, C.D. A technique for using composite DMSP/OLS "city lights" satellite data to map urban area. Remote Sens. Environ. 1997, 61, 361-370. [CrossRef]

3. Farzanegan, M.R.; Fischer, S. Lifting of International Sanctions and the Shadow Economy in Iran-A View from Outer Space. Remote Sens. 2021, 13, 4620. [CrossRef]

4. Gibson, J.; Boe-Gibson, G. Nighttime Lights and County-Level Economic Activity in the United States: 2001 to 2019. Remote Sens. 2021, 13, 2741. [CrossRef]

5. Liu, H.; He, X.; Bai, Y.; Liu, X.; Wu, Y.; Zhao, Y.; Yang, H. Nightlight as a Proxy of Economic Indicators: Fine-Grained GDP Inference around Chinese Mainland via Attention-Augmented CNN from Daytime Satellite Imagery. Remote Sens. 2021, $13,2067$. [CrossRef]

6. Weidmann, N.B.; Theunissen, G. Estimating Local Inequality from Nighttime Lights. Remote Sens. 2021, 13, 4624. [CrossRef]

7. Qi, B.; Wang, X.; Sutton, P. Can Nighttime Satellite Imagery Inform Our Understanding of Education Inequality? Remote Sens. 2021, 13, 843. [CrossRef]

8. Lu, D.; Wang, Y.; Yang, Q.; Su, K.; Zhang, H.; Li, Y. Modeling Spatiotemporal Population Changes by Integrating DMSP-OLS and NPP-VIIRS Nighttime Light Data in Chongqing, China. Remote Sens. 2021, 13, 284. [CrossRef]

9. Wang, Y.; Shen, Z. Comparing Luojia 1-01 and VIIRS Nighttime Light Data in Detecting Urban Spatial Structure Using a Threshold-Based Kernel Density Estimation. Remote Sens. 2021, 13, 1574. [CrossRef]

10. Li, F; Liu, X.; Liao, S.; Jia, P. The Modified Normalized Urban Area Composite Index: A Satelliate-Derived High-Resolution Index for Extracting Urban Areas. Remote Sens. 2021, 13, 2350. [CrossRef]

11. Ma, D.; Guo, R.; Jing, Y.; Zheng, Y.; Zhao, Z.; Yang, J. Intra-Urban Scaling Properties Examined by Automatically Extracted City Hotspots from Street Data and Nighttime Light Imagery. Remote Sens. 2021, 13, 1322. [CrossRef]

12. Rybnikova, N.; Portnov, B.A.; Charney, I.; Rybnikov, S. Delineating Functional Urban Areas Using a Multi-Step Analysis of Artificial Light-at-Night Data. Remote Sens. 2021, 13, 3714. [CrossRef] 